\title{
La comunicación como instrumento de la diplomacia pública
}

\author{
Alfredo A. RodRíGUEZ GómEZ \\ Universidad Camilo José Cela \\ agomez@ucjc.edu
}

Recibido: $11 / 10 / 2012$

Aceptado: 23/01/2013

\begin{abstract}
Resumen
La opinión pública se ha convertido hoy en un factor relevante en las relaciones internacionales. La simbiosis entre diplomacia y medios de comunicación ha acercado al "gran público" a los procesos de la negociación internacional. La evolución tecnológica ha modificado los paradigmas de la comunicación también en la esfera internacional, en donde los actores tienen que aplicar nuevas técnicas y estrategias en su acción exterior para trasladar sus mensajes a la opinión pública global. La acción internacional en nuestros días ya no sólo consiste en gestionar la política exterior de un país, sino también en enviar los mensajes adecuados a los públicos objetivo. En este documento analizamos la comunicación como herramienta de la política exterior, de la diplomacia pública y de la imagen de España en el exterior.

Palabras clave: diplomacia pública, marca España, comunicación, relaciones internacionales, plan estratégico de comunicación integral.
\end{abstract}

\section{Communication as an instrument of Public Diplomacy}

\begin{abstract}
Public opinion has become an important factor in international relations. The symbiosis between diplomacy and media has approached the "general public" to international negotiation processes. Technological evolution has changed the paradigms of communication also in the international sphere, where the actors have to apply new techniques and strategies in its external action to move your messages to the global Public Opinion. International action in our days longer consists not only in managing a country's foreign policy, but also sending a message appropriate to the target audience. In this paper we analyze communication as a tool of foreign policy, public diplomacy and the image of Spain out of its borders. Key words: public diplomacy, Spain Mark, communication, international relations, strategic communication plan.
\end{abstract}

\section{Referencia normalizada}

RODRÍGUEZ GÓMEZ, Alfredo A. (2013): "La comunicación como instrumento de la diplomacia pública". Estudios sobre el mensaje periodístico. Vol. 19. Núm. especial abril, págs.: 953-961. Madrid, Servicio de Publicaciones de la Universidad Complutense.

Sumario: 1. Introducción. 2. Metodología. 3. Marco teórico. 4. Entre la propaganda, las relaciones públicas y la comunicación estratégica. 5. Estrategias de comunicación y diplomacia pública moderna. 6 . Conclusiones. 7. Referencias bibliográficas.

\section{Introducción}

La imagen exterior de un país es una cuestión de Estado. Los actores que intervienen en la consecución de una imagen adecuada son de muy diversa índole y actúan desde campos muy diferentes, como la diplomacia tradicional, la pública, la económica, las acciones comerciales o las de comunicación.

La diplomacia pública es uno de los instrumentos de un Estado para trasladar al en el extranjero, a los diferentes públicos objetivo en función de las coordenadas de la política exterior, la identidad de marca país, lo que tiene un fuerte componente de co- 
municación para el que resulta esencial establecer una estrategia. Es decir, todo país requiere de un plan estratégico de comunicación integral que, en todos los posibles campos de actuación, incluidas las herramientas que conforman la web 2.0, traslade al exterior los mensajes pertinentes, junto a su "identidad corporativa".

La evolución experimentada por la tecnología en los últimos años, apoyada en Internet, en el aumento de la velocidad de conexión y en la universalización de las conexiones, ha supuesto un cambio radical en muchos paradigmas, tanto sociales como económicos o de comunicación. En especial, este último aspecto tiene connotaciones relevantes.

La técnica ha renovado el impulso de este canal con la llegada del " 2.0 " y las implicaciones que el nuevo modelo de Internet tiene en la comunicación. La unidireccionalidad del sistema "emisor-canal-receptor" queda trastocada por la facilidad de responder al emisor en el mismo canal por parte del receptor que, desde ese momento, se convierte a su vez en emisor y viceversa.

Esta realidad no sólo es válida para la comunicación entre empresas y clientes, también es ahora la posibilidad de los estados y las organizaciones internacionales para trasladar al exterior sus estrategias de marca país mediante una nueva vía.

Desde el principio - o casi- de la web, los agentes tradicionales de la política exterior iniciaron, unos con más celeridad que otros, su camino en pos de los ciudadanos en el exterior y los de otros países, subiendo a la web información en forma de sedes electrónicas.

La comunicación institucional en materia de política exterior sufrió, a partir de la generalización de esta vía de comunicación, un cambio sustancial. También surgió la posibilidad de crear otras acciones de "venta", de marketing de un producto muy de moda en este momento: la "marca país".

Se trata de una pequeña revolución en la que este nuevo modelo de comunicación cobra un papel relevante en las acciones de diplomacia pública.

Este documento analiza un modelo de diplomacia que algunos llaman abierta y otros "poder blando", 1 y que guarda una enorme relación con la comunicación de un Estado en su sentido más amplio.

\section{Metodología}

El artículo se encuadra en el desarrollo y aplicación metodológicos del análisis de contenido que aplico en el proyecto de investigación para mi tesis doctoral "Acción cultural exterior y diplomacia pública españolas: 1939-2012”.

\section{Marco teórico}

El término «diplomacia pública», en el sentido que se le da en la actualidad, nació en 1965. Edmund Gullion, diplomático de carrera, lo utiliza en relación con la fundación

${ }^{1}$ Soft power es un término que se utiliza para describir la capacidad de un actor político para incidir en las acciones o intereses de otros actores valiéndose de medios culturales e ideológicos. 
del Edward R. Murrow Center of Public Diplomacy en la Fletcher School of Law and Diplomacy de la Tufts University. El primer folleto del centro describe la práctica de la diplomacia pública como: «Conjunto de estrategias a través de las cuales gobiernos, grupos privados e individuos influyen en las actitudes y opiniones de otros gobiernos e individuos para incidir en sus decisiones de política exterior».

Es decir, relaciona esta actividad con un conjunto de acciones que, en otros tiempos, podrían haberse estudiado perfectamente en Historia de la propaganda (Pizarroso, 1993).

Jill A Schuker resume de un modo muy completo la definición del concepto como «comunicación efectiva con públicos clave alrededor del mundo». Otros autores consideran que puede entenderse esta diplomacia como una modalidad dentro de los instrumentos de la diplomacia contemporánea y, como tal, «una parte importante del esfuerzo de los estados por entenderse entre sí y por promocionar la política exterior y la imagen nacional» (Oviamionayi Iyamu, 2004: 218).

El Ministerio de Asuntos Exteriores alemán define en su web la diplomacia pública de la siguiente manera: «Suma de todas las actividades de comunicación exterior dirigidas a élites o líderes de opinión, y a la opinión pública general que, a largo plazo, tienen la finalidad de influir de manera positiva en la imagen y la percepción de Alemania». Introduce así el concepto «comunicación» en el sentido de facilitar o promover la información como herramienta de este modelo de diplomacia.

Sin embargo Noya (2007: 27) asegura que es una gestión de imágenes; siempre según este autor, «las acciones de diplomacia pública o marca país persiguen proyectar una imagen al servicio de los intereses de la política exterior»; es decir, en el marco de las relaciones internacionales (Noya, 2007, pág. 27). No todos los autores abogan por este término. Richard T. Arndt (2004: 32) afirma que «La omnipresente frase "diplomacia pública" genera confusión y poco más: no he encontrado ninguna definición de ella que sea convincente», para seguir: «Fue creada [...] para describir la labor de la Agencia de Información de Estados Unidos [...] y así evitar el término envenenado de propaganda».

Esta discrepancia, con ser notable, no encuentra eco en otros autores contemporáneos, por lo que parece asegurada la vigencia del término.

La evolución de la situación mundial, la globalización y, en especial los avances tecnológicos configuran un marco extraordinario que es preciso tener en cuenta a la hora de establecer una referencia para la nueva diplomacia pública, que tiene un entorno diferenciado y que no sólo busca influir de forma inmediata en un público extranjero sino que también intenta escuchar a ese público y modificar los enfoques e, incluso, la política, en función de lo que oye del exterior.

Tampoco es ya necesario que las acciones sean sólo encaminadas a mejorar la imagen de un Estado o de un actor internacional, también pueden estar dirigidas a la promoción de una idea -la semiolvidada Alianza de Civilizaciones, o el cambio climático y la cooperación internacional, pueden ser ejemplos- que el actor considera de vital interés en su acción exterior; todo ello alcanzando algún tipo de compromiso con la finalidad de gestionar el entorno internacional. 


\section{Entre la propaganda, las relaciones públicas y la comunicación estratégica} «La diplomacia pública está inevitablemente ligada al poder». Con esta frase empieza el capítulo 1 del Routledge Habdbook of Public Diplomacy, bajo el título Rethinking Public Diplomacy (Snow, Taylor, \& (editores), 2009). Joseph Nye acuñó el término «poder blando» en una de las teorías más importantes que le han otorgado su prestigio como politólogo, la realizada sobre este término, que vio la luz en el libro Bound to Lead: The Changing Nature of American Power (Nye J., 1991), en el que explica que el concepto de poder viene definido por la capacidad de influir en los demás para conseguir que hagan lo uno quiere. Según este autor existen, al menos, tres maneras esenciales de lograrlo:

- la coacción,

- el uso de la recompensa, y

- generar una atracción subjetiva hacia algo que las personas desean llegar a ser.

Ésta última es la que se conoce como poder blando: hacer que otros nos aprecien hasta el punto de lograr que cambien su comportamiento para adecuarlo a nuestros deseos y necesidades.

La relación entre diplomacia pública y la comunicación se muestra con un ejemplo. En los conflictos bélicos hasta casi mediados del siglo XX, dos adversarios enfrentados sólo pensaban en cómo ganar, batalla a batalla, hasta la victoria final; pero la evolución natural de todas las disciplinas ha llegado también al difícil arte de la guerra; tanto que ya casi nadie utiliza esta palabra y prefiere el empleo de eufemismos como «conflicto armado», que suena de un modo más suave aunque describa la misma realidad. La razón es que los mensajes cuentan porque hoy en día los conflictos armados no sólo hay que ganarlos en el campo de batalla, sobre el terreno y ante el enemigo; también hay que hacerlo ante la opinión pública.

Este caso concreto, el de los conflictos bélicos, nos encamina hacia otra cuestión: ante qué opinión pública; es decir, cuáles son las «opiniones públicas» involucradas en este tipo de conflictos. No obstante, consideramos que la respuesta a esta duda es relativamente sencilla, ante todas:

- ante la del propio país o países intervinientes en el conflicto, ante cuya opinión pública hay que justificar la entrada en el conflicto;

- ante la del contrincante, ya que si vencemos en el campo de batalla, debemos conseguir que nuestra imagen frente a los vencidos no sea tan abominable como pueda parecer en un principio.

- cuanto antes logremos vender nuestra «buena imagen», con más facilidad y rapidez alcanzaremos la estabilidad, y ante la de la comunidad internacional, ya que cuanto mejor se vea nuestra imagen en la dimensión internacional, más garantías tendremos de obtener su apoyo.

Abundando en la importancia de la imagen, según Laporte (2007: 1): «La mala imagen internacional de Estados Unidos perjudica la política exterior y pone en riesgo la seguridad nacional» y continúa: «El Departamento de Estado, entre otras estrategias, ha recurrido a la diplomacia cultural para favorecer el entendimiento y difundir los valores democráticos»». 
Para Cull (2009: 55) la diplomacia pública «es un término que se emplea con frecuencia, pero que raras veces se somete a un análisis riguroso»; ante la dificultad de hacerlo, lo descompone en seis factores: escuchar, defender -defensoría, en sus propias palabras-, diplomacia cultural, intercambio y radiodifusión internacional, a los que, al final, añade un séptimo: guerra psicológica.

Las acciones de diplomacia pública no siempre pretenden influir en las masas; en una evidencia de lo que hoy se conoce con el calificativo de «2.0», también se puede buscar la interacción con los públicos objetivo con el fin de escuchar sus opiniones e, incluso, modificar enfoques como consecuencia de tal retroalimentación de forma que, a través de este canal de comunicación se consiga el objetivo de "llegar" a la opinión pública.

Empezamos a movernos en una nueva diplomacia pública que tiene dos características: una es la que indica Nye, la que trabaja en conseguir la credibilidad de los actores internacionales -"la cuestión ya no es quién gana, sino qué historia gana" (Nye, 2010)-, y otra es la posibilidad de uso de las redes sociales para nuestros fines de acción cultural exterior y diplomacia pública. Podríamos llamarla, en un claro guiño a las tendencias actuales, la "diplomacia pública 2.0".

No se trata de meras acciones de propaganda ni unas acciones de relaciones públicas. En su pleno sentido, implica el establecimiento de unas relaciones estables y a largo plazo que permitan la creación de un entorno apropiado para las políticas nacionales. El propio Nye, en el documento arriba referenciado, considera que los gobiernos pueden contribuir a estas acciones de tres formas:

- Mediante una comunicación diaria, primera que consiste en explicar el contexto de las decisiones políticas tanto en el plano nacional como en el internacional. Estas acciones se medirían en horas o, como mucho, en días.

- La segunda es la comunicación estratégica, que desarrolla un conjunto de temas sencillos al igual que se haría en las campañas políticas o en las publicitarias, lo cual sería cuestión de semanas, meses e incluso años.

- La tercera dimensión es el desarrollo de relaciones duraderas con individuos esenciales que pueden tardar incluso décadas, y que implican los lectorados, los intercambios de becas y alumnos, formación, seminarios, conferencia y acceso a los canales mediáticos ${ }^{2}$.

Podemos, por tanto, establecer que la comunicación y la diplomacia pública son instrumentos idóneos para crear buenas relaciones que no son inmediatas pero sí pueden durar mucho tiempo.

\section{Estrategias de comunicación y diplomacia pública moderna}

Como hemos apuntado, la política exterior de un país en nuestros días no sólo está influenciada por las clases políticas dirigentes. En un mundo globalizado en el que la in-

2 Estos programas son lo que el periodista estadounidense Edward R. Murrow llamó en su día los «últimos tres pies» cruciales de las comunicaciones cara a cara, con la credibilidad realzada que crea la reciprocidad. 
formación, como hemos apuntado, circula libremente por los diversos canales y llega al ciudadano de manera casi instantánea, los sujetos antes pacientes de esa política exterior, los propios ciudadanos, se han convertido en opinadores activos. Un claro ejemplo fueron, en su día, las manifestaciones contra la Guerra de Irak en todo el mundo.

Como este, podríamos citar numerosos ejemplos de comunicación/activismo en la red. Sin ir más lejos, los cientos de millones de comentarios suscitados a raíz de la Primavera Árabe que, por cierto, se inició en Túnez con acciones 2.0.

Los medios de comunicación no tradicionales desempeñan cada día un papel más relevante en la creación de opinión. La Red los ha multiplicado exponencialmente y ha convertido determinadas redes sociales y blogs en fuente y canal de información. Se trata del conocido como periodismo ciudadano.

Los sujetos protagonistas en la creación de opinión pública en tiempos pretéritos estaban en manos de elites con capacidad de decisión: gobiernos, grandes empresarios o intelectuales de reconocido prestigio y un grupo de segundo orden: directores de medios, profesores, escritores y profesionales similares. (Pereira, 2012: 278). Hoy, hay un sistema de creación de opinión más universal e incontrolable que también tiene una enorme influencia en la identidad de un país y, por tanto, en la imagen de ese país en el exterior. Para Castells (2009: 536), la relación de "las instituciones con la cultura de su sociedad y economía" es una parte esencial del poder. Pues bien, una parte de ese poder es el que se ejerce en el campo de las relaciones internacionales y, de él, y en materia de política exterior, hoy cobra especial importancia las estrategias de comunicación en las acciones de diplomacia pública.

Este modelo de diplomacia está crecientemente ligado a los medios de comunicación $^{3}$. La acción exterior del Estado, relegada antaño a la relación entre elites, ha evolucionado en un mundo globalizado tras sufrir las consecuencias del nuevo paradigma comunicacional.

El cambio en la forma de ocupar los canales de comunicación entre emisor y públicos objetivos se ha producido de modo que se requieren nuevas estrategias que incluyan las herramientas que hoy están a nuestra disposición de forma casi gratuita.

Judith McHale, dijo ante el Congreso norteamericano en su discurso de aceptación del cargo de subsecretaria de Diplomacia Pública de la Administración Obama que "la nueva tecnología, utilizada de forma eficaz y creativa, puede suponer una revolución. Los avances en materia de comunicación proporcionan oportunidades sin precedentes para implicar directamente a las personas, para conectar unas con otras y para sacar el máximo rendimiento a los diversos esfuerzos en materia de diplomacia pública tradicional".

Es un ejemplo de discurso que evidencia la oportunidad estratégica que supone el uso de las herramientas que la tecnología 2.0 pone al alcance de la diplomacia en sus más variadas facetas.

${ }^{3}$ El Gobierno Rajoy creó la Dirección General de Diplomacia Pública y Medios de Comunicación en el MAEC, lo que da idea de esa unión entre acciones de diplomacia pública y su relación con los medios. 
De esta forma, los esfuerzos diplomáticos no sólo deben aprovechar la web y las herramientas de Internet, como las redes sociales, para difundir mensajes, al más puro estilo de una comunicación trasnochada. También, y esto es imprescindible, deben introducirse de lleno en el universo $2.0 \mathrm{y}$, por tanto, escuchar, interactuar y ser activos en las redes, que en ello se basa la bidireccionalidad de la comunicación de nuestros días.

\section{Conclusiones}

La diplomacia, en su faceta pública es decir abierta a la sociedad y a los diferentes agentes sociales, económicos, políticos y culturales, debe aprovechar los cauces de comunicación que tiene a su disposición en el siglo XXI, ya que es el lugar en el que está una buena parte de la opinión pública y, por tanto, los distintos públicos objetivo. Sin olvidar los cauces de participación institucional tradicional, plenamente vigentes, será imprescindible hacer uso de "lo 2.0" para alcanzar más y mejor a esos públicos objetivo.

Blogs, redes sociales, microblogging, agregadores de contenido, herramientas de medición de la reputación en línea y demás instrumentos contemporáneos, deben formar parte de la vida diaria de nuestros actores en materia internacional para conquistar, en las estrategias de comunicación, los corazones de la opinión pública en el exterior.

El país, la región, la ciudad de origen de un producto pueden constituir un sello de calidad adicional a la propia marca; es más, pueden ser el elemento diferenciador por excelencia de ese producto con respecto a la competencia. También pueden ser elemento de distinción - positivo o negativo- de una marca.

Tras los trágicos sucesos del 11 de septiembre de 2001, Colin Powell, a la sazón secretario de defensa norteamericano, definió la diplomacia con estas palabras: "Estamos vendiendo un producto. El producto que vendemos es la democracia". (Saavedra Torres, 2012). Es decir, la "marca zona", si generalizamos el término, se ha convertido en un elemento de estrategia en que la comunicación es factor esencial. Y no sólo en lo económico. Powell evidenció, con ese comentario, que también es esencial en lo político.

Por otra parte, el mundo complejo en que vivimos, global, abierto, interrelacionado, hace de la comunicación un instrumento de valor incalculable para la diplomacia abierta; es decir, la que se dirige esencialmente a la opinión pública. Además, el peso de esa opinión pública es, a día de hoy, de vital importancia para los gobernantes.

La imagen exterior de un país puede ser un elemento determinante ya que influye decisivamente y de un modo directo en su economía -turismo, exportaciones, etc.-. Y esa imagen se consigue a través de la transmisión de identidades y mensajes.

Internet, como soporte contemporáneo de la comunicación, ha supuesto un cambio radical en el modelo comunicacional, tanto por la ampliación de los canales de transmisión, la ausencia de fronteras físicas, su acceso universal, su inmediatez y por su bajo coste, como por la bidireccionalidad de la comunicación.

La aparición del llamado "periodismo ciudadano" -para muchos, una mera fuente de información-, constituye otro elemento de sustancial importancia que viene a aña- 
dirse a las estructuras informativas. Todo ello supone el afianzamiento de un modelo de diplomacia a caballo entre la propaganda, el marketing y la comunicación, que rompe fronteras y permite, a la vez que exige, establecer estrategias en el exterior para "conquistar" el corazón y los sentimientos de nuestro público objetivo con el fin de que actúen en nuestro favor y con el objeto de conseguir que la imagen de marca del país sea un hecho diferenciador positivo en los diversos órdenes: cultural, comercial, económico, turístico y perceptivo.

\section{Referencias bibliográficas}

ARNDT, Richard T. (2004): “¿Cultura o propaganda? Reflexiones sobre medio siglo de diplomacia cultural de Estados Unidos". Revista mexicana de política exterior, $n^{\circ} 85,29$ - 54 .

CASTELLS, Manuel (2009): Comunicación y poder. Madrid, Alianza Editorial.

CULL, Nicholas J. (2009): "Diplomacia pública: consideraciones teóricas". Revista Mexicana de Política Exterior, $n^{\circ} 85,55$ - 93.

DELGADO GÓMEZ-ESCALONILLA, Lorenzo (1992): Imperio de papel: acción cultural y politica exterior durante el primer franquismo. Madrid, CSIC.

LA PORTE, Teresa (2007): "La diplomacia pública americana: lecciones para una comunicación internacional". Comunicación y Sociedad, vol. XX, núm. 2. Pamplona, Universidad de Navarra, en: http://www.unav.es/fcom/comunicacionysociedad/es /articulo.php?art_id=43\#C01. [Consultado: 31 de enero de 2011]

MARÈS, Antoine (2003): "La culture comme instrument de la politique extérieure des démocraties populaires: l'exemple franco-tchécoslovaque". Relations Internationales, 115 - Diplomatie et transferts culturels au XXème siècle - 1 . Septembre-octobre.

NOYA, Javier (2007): Diplomacia pública para el siglo XXI. Barcelona, Ariel.

NOYA, Javier (2005): El poder simbólico de las naciones. Obtenido de DT 35/2005 - Real Instituto Elcano: http://www.realinstitutoelcano.org/

NOYA, Javier (2002): La imagen de España en el Exterior. Estado de la cuestión. Madrid, Real Instituto Elcano.

NOYA, Javier (2012): Ni tanto ni tan poco. Madrid, Real Instituto Elcano: http://www.realinstitutoelcano.org (1 de mayo) [Consultado: 30 de mayo de 2012]

NYE, Joseph S. (1991): Bound To Lead: The Changing Nature Of American Power. New York, Basic Books.

NYE, Joseph S. (2003): La paradoja del poder norteamericano. Madrid, Taurus.

NYE, Joseph S. (2010): “The New Public Diplomacy”, de Project Syndicate. A World of Ideas: http://www.project-syndicate.org/commentary/nye79/English [Consultado: 17 de mayo de 2011]

OLIVIÉ, Iliana; MACÍAS, Carlos M.; y PÉREZ, Aitor (2012): “¿Qué hacen (y qué pueden hacer) las empresas españolas en el exterior? Inversión extranjera, des- 
arrollo e imagen-país". Real Instituto Elcano: http://www.realinstitutoelcano.org/ [Consultado: 24 de junio de 2012]

OVIAMIONAYI IYAMU, Victgor (2004): "Diplomacia pública en la bibliografía actual". Ámbitos, $n^{\circ} 11-12$, 215-236. Sevilla, Universidad de Sevilla

PEREIRA, Juan Carlos (2012): La política exterior de España. De 1800 hasta hoy (2a edición). Barcelona, Ariel.

PIZARROSO, Alejandro (1993): Historia de la propaganda. Madrid, Eudema.

RODRÍGUEZ GÓMEZ, Alfredo y FERNÁNDEZ VÁZQUEZ, Jorge J. (2012): "La imagen de España a través del deporte y su protocolo". EmásF: revista digital de educación física, , $\mathrm{n}^{\mathrm{o}} 15$, pp. 21-33.

RODRÍGUEZ GÓMEZ, Alfredo (2009): “Imagen esterior de España a través de sus Fuerzas Armadas". Conferencia con motivo del centenario de la Asociación de la Prensa de Galicia . (No publicada). Vigo, Pontenvedra, España.

SAAVEDRA TORRES, José Luis (2012): "El poder blando de la marca país: del marketing a la diplomacia pública". REDMARKA UIMA - Universidad de A Coruña año $\mathrm{V}, \mathrm{n}^{\circ} 8,133-148$.

SNOW, Nancy y TAYLOR, Philip M. (editores, 2009): Routledge Handbook of Public Diplomacy. New York, Routledge.

VAN HAM, Peter (2003): "Mejorar la imagen de EEUU tras el 11-S: el papel de la diplomacia pública". ARI n $n^{\circ}$ 55/2003. Madrid, Real Instituto Elcano.

\section{Alfredo A. RODRÍGUEZ GÓMEZ}

Universidad Camilo José Cela

Profesor asociado

Doctorando en Derecho Internacional Público y Relaciones Internacionales por la UNED. Doctorando en Comunicación Audiovisual por la Universidad Complutense de Madrid agomez@ucjc.edu 